\title{
Aquatic Habitat Bird Occurrences at Photovoltaic Solar Energy Development in Southern California, USA
}

\author{
Karl Kosciuch *D, Daniel Riser-Espinoza, Cyrus Moqtaderi and Wallace Erickson \\ Western EcoSystems Technology, Inc., Cheyenne, WY 82001, USA; despinoza@west-inc.com (D.R.-E.); \\ cmoqtaderi@west-inc.com (C.M.); werickson@west-inc.com (W.E.) \\ * Correspondence: kkosciuch@west-inc.com
}

check for updates

Citation: Kosciuch, K.; Riser-Espinoza, D.; Moqtaderi, C.; Erickson, W. Aquatic Habitat Bird Occurrences at Photovoltaic Solar Energy Development in Southern California, USA. Diversity 2021, 13, 524. https://doi.org/10.3390/ d13110524

Academic Editor: W. Douglas Robinson

Received: 4 August 2021

Accepted: 21 October 2021

Published: 23 October 2021

Publisher's Note: MDPI stays neutral with regard to jurisdictional claims in published maps and institutional affiliations.

Copyright: (c) 2021 by the authors. Licensee MDPI, Basel, Switzerland. This article is an open access article distributed under the terms and conditions of the Creative Commons Attribution (CC BY) license (https:// creativecommons.org/licenses/by/ $4.0 /)$.

\begin{abstract}
The development of photovoltaic (PV) utility-scale solar energy (USSE) in the desert Southwest has the potential to negatively affect birds through collision mortality. Based on early patterns in fatality monitoring data, the lake effect hypothesis (LEH) was developed and suggested that birds misinterpret PV solar panels for water. As the LEH was only recently defined and inference beyond bird mortality is limited, our research objective was to examine the species composition, abundance, and distribution of live and dead aquatic habitat birds at five PV solar facilities and paired reference areas in southern California. Further, we collected data from a small regional lake as an indicator of the potential aquatic habitat bird community that could occur at our study sites. Using an ordination analysis, we found the lake grouped away from the other study sites. Although the bird community (live and dead) at the solar facilities contained aquatic habitat species, Chao's diversity was higher, and standardized use was more than an order of magnitude higher at the lake. Finally, we did not observe aquatic habitat bird fatalities in the desert/scrub and grassland reference areas. Thus, the idea of a "lake effect" in which aquatic habitat birds perceive a PV USSE facility as a waterbody and are broadly attracted is likely a nuanced process as a PV solar facility is unlikely to provide a signal of a lake to all aquatic habitat birds at all times.
\end{abstract}

Keywords: photovoltaic solar; birds; fatality; lake effect; attraction; development

\section{Introduction}

The development of photovoltaic (PV) utility-scale solar energy (USSE) in the desert Southwest of the United States of America (USA.) was thought to have the potential to negatively affect birds through habitat loss, habitat fragmentation, and collision mortality with infrastructure, similar to other forms of energy development [1]. Although bird mortality was anticipated, the discovery of stranded or dead waterbirds was not expected as PV USSE facilities do not contain water-settling ponds as are found with other types of energy development, such as oil and gas production [2]. In a summary of bird carcasses that were opportunistically obtained from three USSE solar facilities (two concentrating solar power and one PV) in California, U.S., Kagan et al. [3] determined that 48\% (27/56) of identifiable remains found at the Desert Sunlight PV USSE facility (hereafter Desert Sunlight) in California, U.S., were of aquatic habitat birds that foraged in water. The carcasses from Desert Sunlight included species that rely on water for takeoff and landing (e.g., family Gaviidae) and those that use water for some aspect of their life history (e.g., family Charadriidae); these groups are defined by Kosciuch et al. [4] as water obligates and water associates, respectively.

The detection of water-obligate and water-associate bird carcasses raised questions about the causal mechanisms responsible for the species' occurrence because PV solar panels are typically within $4 \mathrm{~m}(\mathrm{~m})$ of the ground and do not represent a vertical hazard in the airspace similar to other forms of anthropogenic development, such as buildings [5], communication towers [6], and wind turbines [7,8]. Further, Desert Sunlight is located in 
a desert ecosystem that lacks many permanent large waterbodies. In their report, Kagan et al. [3] stated that the solar panels might be "reminiscent" of bodies of water because some species of aquatic habitat birds (a broad group of birds including water associates and water obligates) should not occur on the ground in a desert environment. An article formalized the idea as "lake effect", concluding that birds mistake a reflective PV USSE facility for a waterbody [9]. The outcome of a "lake effect" at PV USSE facilities could include negative effects on aquatic habitat birds if the causal mechanism occurs broadly across PV USSE facilities and bird species.

The lake effect hypothesis (LEH), which posits that aquatic habitat birds are attracted to PV solar facilities, was used to explain the occurrence of aquatic habitat bird carcasses at PV USSE facilities; however, no data existed at the time to understand how birds perceive PV USSE facilities, nor were alternative hypotheses proposed. Further, as the LEH was developed based on one PV USSE facility, it was unknown whether the occurrence of aquatic habitat birds was unique to Desert Sunlight or whether the pattern was widespread among PV USSE facilities in southern California, U.S. In a summary of 13 studies at 10 PV USSE facilities in the Southwestern U.S., Kosciuch et al. [4] determined that carcasses of water-obligate birds were documented in 90\% (9/10) of studies in the Sonoran and Mojave Desert (SMD) Bird Conservation Region (BCR), the region where Desert Sunlight is located. However, Kosciuch et al. [4] found that water obligates were detected in only one of three studies outside the SMD BCR. Thus, uncertainty remains in how broadly the LEH can be applied and whether the LEH applies to all aquatic habitat birds or is limited to specific species.

As the LEH was only recently defined and inference beyond bird mortality is limited, our research objective was to examine the species composition, abundance, and distribution of live and dead aquatic habitat birds at five PV solar facilities and paired reference areas in southern California. Further, we collected data from a small regional lake as an indicator of the potential aquatic habitat bird community that could occur at our study sites. Including live bird surveys in our study was an important advancement in investigating the LEH because the risk profile differs among aquatic habitat birds. For example, species that forage over water (e.g., tree swallow (Tachycineta bicolor)) are at lower collision risk and are less likely to be represented in fatality data even if they were attracted to the facility than species that land on water (e.g., western grebe (Aechmophorus occidentalis)). It is unknown how the aquatic habitat bird diversity and abundance at PV USSE facilities compares with that at a regional waterbody; thus, our objective was to understand whether a local lake could provide context for our findings at the PV study sites. Our final objective was to determine whether there was support for the alternative hypothesis that exhausted or sick aquatic birds landed broadly on the landscape and died, but were only detected at PV USSE facilities because researchers did not search outside the facilities (e.g., [4]). Searching for aquatic habitat bird carcasses in reference areas outside the PV solar sites would allow us to determine whether there was support for an alternative hypothesis that posits mortality was not predicated on birds being attracted to the PV solar facility.

\section{Materials and Methods}

Our study was conducted in 2018 and 2019 at PV USSE facilities and paired reference areas in southern California, USA. (Figure 1), during the fall migration period in each year. Kosciuch et al. [4] demonstrated that aquatic habitat bird fatalities peak in fall between 2 September and 11 November in the Southwestern USA Thus, as our study was intended to understand aquatic habitat bird responses to PV solar facilities, we conducted monitoring at our study sites from 18 September to 1 November 2018 and 23 September to 1 November 2019. We monitored each study site for a 2-week focal period within the fall migration period, alternating between live bird surveys and fatality surveys. During each week, three fatality surveys and two point count surveys were conducted for a total of six fatality surveys and four point count surveys per study site. Slight variations in survey frequency occurred due to weather and scheduling logistics. 


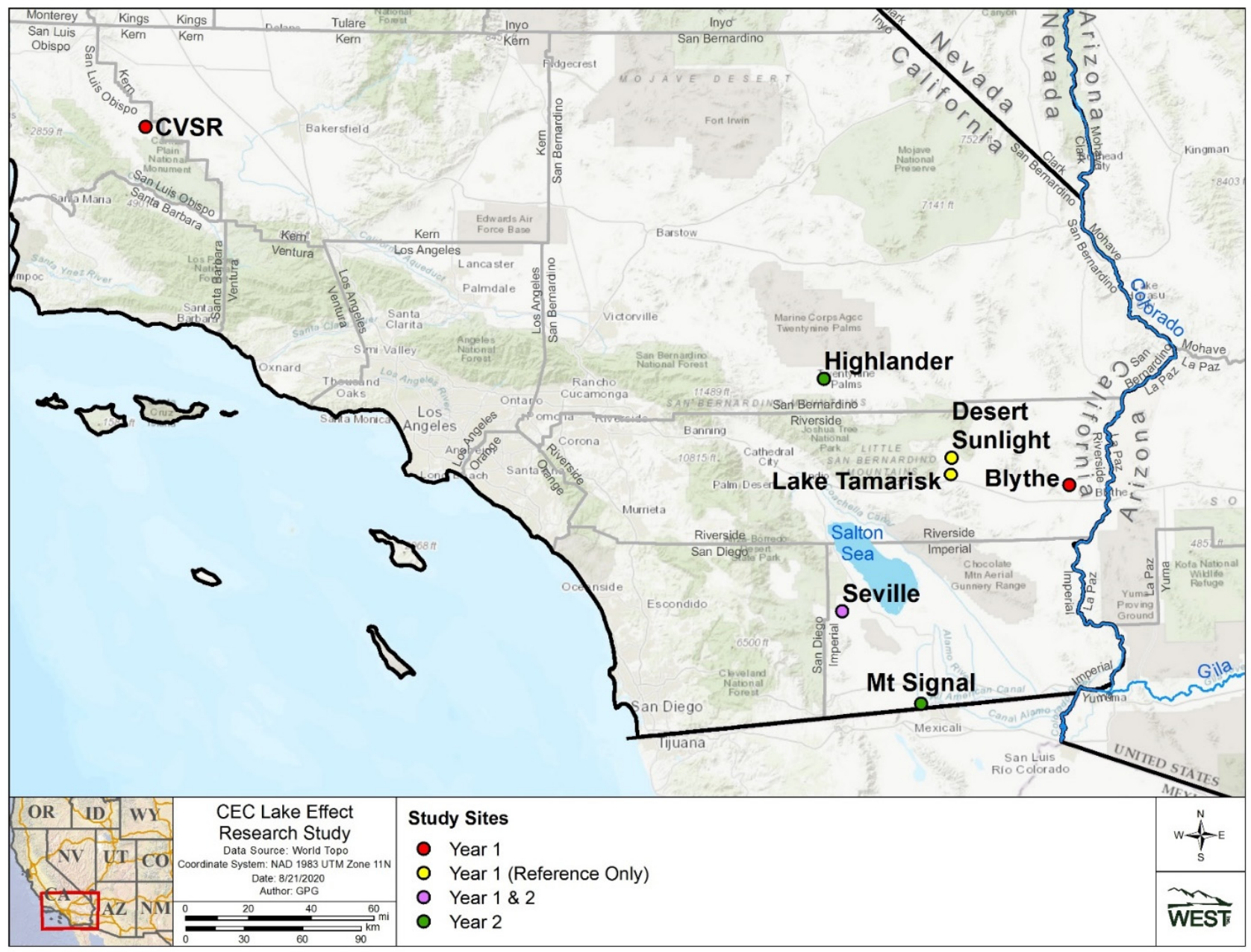

Figure 1. Study site locations in California, USA, 2018-2019.

\subsection{Study Sites}

In 2018, our PV USSE study sites included the Blythe Solar Energy Center (Blythe; 235 megawatts (MW)) located in Riverside County, California; California Valley Solar Ranch (CVSR; 250 MW) located in San Luis Obispo County, California; and Seville 1 and Seville 2 Solar (treated as one site called Seville; $50 \mathrm{MW}$ ) located in Imperial County, California. A matched pairs design was implemented by selecting a paired reference area for each study site using the criteria of being at least $1 \mathrm{~km}(\mathrm{~km})$ from an operational PV USSE facility and composed of similar vegetation communities as found within the facility prior to construction [10]. We selected reference areas that did not contain a solar facility and had limited anthropogenic features that could result in aquatic habitat bird mortality.

In addition, we monitored two reference areas in 2018 that were not paired with a PV USSE facility, the desert habitat outside of Desert Sunlight (hereafter Reference A) in Riverside County, California, and Lake Tamarisk in Riverside County. Reference A was selected as it is near Desert Sunlight, where 94 water-associate and water-obligate bird carcasses and injuries were detected during the first 2 years of fatality monitoring [4]. We selected Lake Tamarisk, an approximately 5.5 ha artificial lake located approximately $6.4 \mathrm{~km}$ away from the nearest PV USSE facility, as an indicator of the species composition and abundance of birds at a waterbody local to our study sites. In 2019, our PV USSE study sites included one studied in 2018 (Seville) and two new sites that included Highlander II (Highlander; 10 MW) in San Bernardino County, California, and Mt. Signal 3 (Mt. Signal; $328 \mathrm{MW}$ ) in Imperial County, California. The same criteria were used to select reference areas in 2019. Given the agricultural landscape in the Imperial Valley, it was challenging to locate reference areas without anthropogenic features. Thus, our reference area for Mt. 
Signal contained anthropogenic features; however, these features were present at the solar site prior to development. Data were not collected at Reference A or Lake Tamarisk in 2019. We assigned each site to one of three general habitat classes based on dominant vegetation on the surrounding landscape: grassland, desert/scrub, and agriculture. Blythe, Seville, Mt. Signal, and Highlander were desert/scrub; Mt. Signal was agriculture; and CVSR was grassland. Lake Tamarisk is an artificial lake, and we did not include it in one of the three habitat categories, but it occurs in a desert/scrub habitat.

To understand whether there was a relationship between the amount of water on the landscape and the occurrence of aquatic habitat bird mortality, we used the 2016 National Land Cover Database (NLCD) [11,12] to calculate the hectares of land cover types based on NLCD classification. For each area, we generated the minimum convex polygon (MCP) around all surveyed areas (facility and reference, where applicable). Next, we calculated the amount of area within a $5 \mathrm{~km}$ buffer of each MCP occupied by each represented 2016 NLCD land cover type and the percentage of the total area with the $5 \mathrm{~km}$ buffer occupied by each land cover type. Only three NLCD land cover types associated with aquatic habitats were represented across the seven sites in our study: emergent herbaceous wetlands, open water, and wood wetlands (Table 1). Mt. Signal, the agricultural site, had the greatest amount (609 ha) and proportion of area occupied (2.23\%) by aquatic habitat land cover types within the $5 \mathrm{~km}$ buffered MCP. Blythe, in a desert/scrub habitat, had the least representation of aquatic habitat land cover types (0.09 ha, $0.001 \%)$. The land cover data also confirmed Lake Tamarisk is a relatively isolated waterbody, being the only aquatic habitat (6.3 ha, $0.08 \%)$ within the $5 \mathrm{~km}$ buffered MCP around the lake survey points.

\subsection{Fixed-Point Count Surveys}

The objective of fixed-point count surveys was to collect data to evaluate patterns of live aquatic habitat bird use at the PV USSE study sites and reference areas. We established and surveyed $10 \mathrm{~min}$ fixed-point count locations (with a survey defined as one complete 10 min observation period at an individual $10 \mathrm{~min}$ point location) within each solar facility and at the reference areas [13]. Point count locations were determined by randomly sampling coordinates within facility boundaries and polygons defining accessible public or private land for reference areas. At Mt. Signal, point count locations were selected along roads adjacent to reference areas due to land access limitations. The number of point count locations was based on PV solar facility size and varied among study sites (Supplementary Material Table S1). In addition, in 2019 we added one 60 min fixed long-sit point count at each study site to increase the likelihood of observing aquatic habitat bird behavior, such as approaching the PV solar facility (with a survey defined as one complete $60 \mathrm{~min}$ observation period at an individual $60 \mathrm{~min}$ long-sit point location). The long-sit point count was situated such that the surveyor was able to observe birds flying over the solar facility and the surrounding habitat. In 2018 and 2019, 10 min point count locations were surveyed four times each (thus, a total of 40 observation minutes per location) during the study period. Long-sit point count sites were surveyed in 2019 only and were surveyed two times each (thus, a total of 120 observation minutes per location) during the study period. During both 10 and 60 min counts, we limited observations for small birds to within a $100 \mathrm{~m}$ radius from an observer; no limit was imposed (i.e., unlimited distance) for observations of large birds (e.g., family Podicipedidae). The number of 10 min points surveyed per day varied dependent on the study site, but typically ranged between 10 and 15 points surveyed per day. Surveys for all 10 min point count locations typically commenced $30 \mathrm{~min}$ before sunrise and were conducted no later than $4 \mathrm{~h}$ after sunrise. Long-sit point counts were conducted once during the sunrise period (between $30 \mathrm{~min}$ prior and no more than $4 \mathrm{~h}$ after sunrise) and once during the mid-day or evening period (within $6 \mathrm{~h}$ of sunset) to capture temporal differences in flight patterns. 


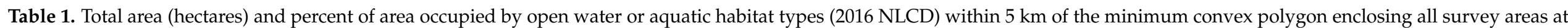
sites monitored, 2018-2019.

\begin{tabular}{|c|c|c|c|c|c|c|c|c|c|c|c|c|c|c|c|c|}
\hline \multirow{3}{*}{$\begin{array}{l}\text { Aquatic Habitat Type } \\
\text { (2016 NLCD) }\end{array}$} & \multicolumn{8}{|c|}{ Desert/Scrub } & \multicolumn{4}{|c|}{ Grassland } & \multirow{2}{*}{\multicolumn{2}{|c|}{$\begin{array}{l}\text { Agricultural } \\
\text { Mt. Signal } 3\end{array}$}} & \multirow{2}{*}{\multicolumn{2}{|c|}{ Total }} \\
\hline & \multicolumn{2}{|c|}{ Blythe } & \multicolumn{2}{|c|}{ Highlander II } & \multicolumn{2}{|c|}{ Seville } & \multicolumn{2}{|c|}{ Reference A } & \multicolumn{2}{|c|}{ Lake Tamarisk } & \multicolumn{2}{|c|}{ CVSR } & & & & \\
\hline & Area & $\%$ & Area & $\%$ & Area & $\%$ & Area & $\%$ & Area & $\%$ & Area & $\%$ & Area & $\%$ & Area & $\%$ \\
\hline Barren Land & 2929.50 & 16.59 & 8898.36 & 60.88 & $14,977.13$ & 95.63 & 1811.56 & 10.95 & 52.43 & 0.64 & 556.29 & 3.25 & 2885.69 & 10.58 & $14,977.13$ & $27.43 \%$ \\
\hline Cultivated Crops & 117.40 & 0.66 & & 0.00 & 118.28 & 0.76 & - & 0.00 & - & 0.00 & 161.68 & 0.95 & $12,124.00$ & 44.46 & 118.28 & $10.70 \%$ \\
\hline Deciduous Forest & - & 0.00 & 0.90 & 0.01 & - & 0.00 & - & 0.00 & - & 0.00 & - & 0.00 & 0.54 & 0.00 & - & $0.00 \%$ \\
\hline $\begin{array}{l}\text { Developed, High } \\
\text { Intensity }\end{array}$ & 17.04 & 0.10 & 25.83 & 0.18 & 0.63 & 0.00 & 27.44 & 0.17 & 3.51 & 0.04 & 0.84 & 0.00 & 91.35 & 0.33 & 0.63 & $0.14 \%$ \\
\hline $\begin{array}{l}\text { Developed, Medium } \\
\text { Intensity }\end{array}$ & 71.73 & 0.41 & 80.55 & 0.55 & 82.25 & 0.53 & 198.59 & 1.20 & 32.44 & 0.40 & 1.39 & 0.01 & 540.68 & 1.98 & 82.25 & $0.86 \%$ \\
\hline Developed, Open Space & 1107.89 & 6.27 & 1591.03 & 10.89 & 99.80 & 0.64 & 625.56 & 3.78 & 98.89 & 1.21 & 2013.04 & 11.77 & 1612.27 & 5.91 & 99.80 & $6.11 \%$ \\
\hline $\begin{array}{l}\text { Emergent Herbaceous } \\
\text { Wetlands }\end{array}$ & - & 0.00 & - & 0.00 & 0.72 & 0.00 & - & 0.00 & - & 0.00 & 12.58 & 0.07 & 88.19 & 0.32 & 0.72 & 0.09 \\
\hline Evergreen Forest & - & 0.00 & 0.09 & 0.00 & - & 0.00 & - & 0.00 & - & 0.00 & - & 0.00 & 2.70 & 0.01 & - & 0.00 \\
\hline Hay/Pasture & 11.97 & 0.07 & 2.07 & 0.01 & 8.63 & 0.06 & - & 0.00 & 9.00 & 0.11 & 0.36 & 0.00 & 1398.05 & 5.13 & 8.63 & 1.22 \\
\hline Open Water & 0.09 & 0.00 & 24.91 & 0.17 & 0.63 & 0.00 & 3.15 & 0.02 & 6.30 & 0.08 & 0.09 & 0.00 & 45.46 & 0.17 & 0.63 & 0.07 \\
\hline Shrub/Scrub & $12,389.26$ & 70.15 & 3654.09 & 25.00 & 329.55 & 2.10 & $13,089.43$ & 79.13 & 7894.04 & 96.20 & 808.78 & 4.73 & 1324.14 & 4.86 & 329.55 & 33.73 \\
\hline Unclassified & - & 0.00 & - & 0.00 & - & 0.00 & - & 0.00 & - & 0.00 & & 0.00 & 5506.45 & 20.19 & & 4.70 \\
\hline Woody Wetlands & - & 0.00 & 2.70 & 0.02 & 14.62 & 0.09 & - & 0.00 & - & 0.00 & & 0.00 & 474.59 & 1.74 & 14.62 & 0.42 \\
\hline Total & $17,660.82$ & 100.00 & $14,615.57$ & 100.00 & $15,661.60$ & 100.00 & $16,542.57$ & 100.00 & 8206.15 & 100.00 & $17,107.52$ & 100.00 & $27,271.83$ & 100.00 & $15,661.60$ & 100.00 \\
\hline
\end{tabular}




\subsection{Fatality Surveys}

The objective of fatality surveys was to collect data to understand the distribution of aquatic habitat bird carcasses inside and outside of PV USSE facilities. We used distance sampling [14-16] to search for carcasses and feather spots (hereafter "detections") of birds in facility and reference areas. Distance sampling is well suited to PV USSE facilities, especially when vegetation is low or nonexistent and other visual barriers are absent, as it allows for efficient sampling of large areas. The design of PV USSE facilities is also amenable to distance sampling, in that a surveyor can walk perpendicular to PV panel rows and look down each row for potential detections. For each facility study site, a viewshed (maximum distance to search during distance sampling surveys) was established based on the length of the typical panel row at the facility. For reference areas, the viewshed was always $100 \mathrm{~m}$, with the exception of CVSR, where the viewshed was $50 \mathrm{~m}$ due to visibility limitations associated with vegetation density. Cumulatively, we sampled approximately 546 ha of the PV USSE facilities and 1038 ha of the reference areas; the area sampled varied by facility and was based on the field schedule and facility size (Supplementary Material Table S2).

Biologists completed fatality surveys consistent with established protocols for monitoring at PV solar facilities [16]. Within the PV USSE facilities, biologists surveyed arrays of PV solar panels on foot, traveling approximately $0.9 \mathrm{~m} / \mathrm{s}$. Sampled arrays were surveyed from roads bordering the north or south edge of the solar panel array. Biologists walked perpendicular (east or west) to the edge of the solar array and scanned between each row for potential mortalities. During the survey, the biologist scanned out to the maximum viewshed specific to the study site. Surveys in the paired reference areas were conducted to mimic surveys in the solar arrays. Thus, the surveyor walked $0.9 \mathrm{~m} / \mathrm{s}$ along an east-west transect and scanned north or south into the reference area, in the same manner used when scanning between solar panel rows. Due to safety restrictions, biologists were not able to access interior sections of the solar arrays or the reference areas at the Mt. Signal study site. Survey methodology was unaffected, but data collection had to be completed from a distance, aided as best as possible by high-powered optics $(10 \times$ binoculars and a $60 \times$ spotting scope).

During fatality monitoring, not all carcasses are detected by searchers due to observers failing to see a carcass, or a carcass being removed between searches. Thus, searcher efficiency and carcass persistence are measured to adjust for detection bias in fatality studies [16]. Given that carcass persistence times were typically at least 1-2 days for even the smallest trial birds at other solar projects [17-21], we did not measure carcass persistence because we assumed that most fatalities would persist through the average search interval (48 h). Searcher efficiency trials were deployed in facility and reference areas to measure potential differences in the detectability of carcasses between areas within study sites.

\subsection{Searcher Efficiency Trials}

We conducted searcher efficiency trials to calculate the probability that a carcass present in a search area is detected. Searcher efficiency trials are typically conducted with actual bird carcasses; however, given logistical constraints associated with travel between study sites, we used a variety of surrogates to mimic species that could occur at each study site, including Dokken waterfowl trainers (Dokken Dog Supply Inc., Northfield, Minnesota) and characteristically appropriate birds obtained from craft stores similar to passerines typically encountered as detections at PV USSE facilities. Surrogates were chosen to represent small (average weight $\leq 100 \mathrm{~g}$ ) and large (average weight $>100 \mathrm{~g}$ ) bird species typically or expected to be encountered. Whenever possible, surrogates were modified by hand to better resemble actual detections. Modifications included color modification to better represent the local species and the attachment of feathers to the body of the surrogate to represent a fatality posture. Trials were administered prior to surveys by a biologist not otherwise involved with the day's fatality surveys. The biologist conducting fatality surveys was unaware of the time or location of surrogate deployments, or of the number of 
surrogates being dropped [22]. All biologists participating in fatality surveys were tested multiple times throughout each study period.

\subsection{Data Analysis}

We defined habitat associations for all birds detected during our study similar to other studies on bird communities $[23,24]$. To provide a consistent and reproducible categorization of habitat association, we used the "Habitat" information under the "Life History" tab on the Cornell Lab of Ornithology's All About Birds website [25]. We considered aquatic habitat species those that associate with lakes and ponds, marshes, rivers and streams, and shorelines. The species classified as aquatic habitat species in this study were consistent with species classified as water associates and water obligates in Kosciuch et al. [4].

We calculated a metric of use for each aquatic habitat species by site and facility or reference area. We did not calculate density estimates because our dataset included flying individuals and rarely included perched individuals. We acknowledge that detection could have differed among species, but we assumed similar detection for an aquatic habitat species between the PV solar sites and reference areas because we were focused on birds in flight above the solar panels and vegetation. For each species, we summed the count of birds by point and visit (including flyovers), averaging over all points within a survey, and then averaging across all surveys (four surveys at each site in each year of study). We then averaged over sites within a habitat category (desert, grassland, or agriculture) and calculated relative frequencies of point count observations of aquatic habitat species in facility and reference areas within each ecoregion. Relative frequencies were calculated as the averaged use value for each aquatic habitat species divided by the sum of use values for facility and reference areas, respectively. Furthermore, we calculated species richness and Chao's estimator of richness $\left(S_{\text {chao } 1}\right)[26,27]$ (using the "vegan" package in R [28]) to assess the bird communities across the sampled sites. Species richness was calculated as the number of unique identifiable aquatic habitat species by site and facility or reference area. We also used counts of aquatic habitat species to test the null hypothesis that aquatic habitat birds would occur as frequently at the PV solar site as the paired reference area by performing a Cochran-Mantel-Haenszel test (significance level $\alpha=0.10$ ) on the aquatic habitat bird count data. We tabulated the counts of aquatic and nonaquatic habitat birds into bins by facility or reference and habitat category (desert, agriculture, or grassland). We visualized the live aquatic habitat bird community using unconstrained ordination based on latent variable models with the boral (Bayesian ordination and regression analysis) package in $\mathrm{R}$ to determine whether any of the PV facility sites grouped with the lake $[29,30]$.

For fatality surveys, detections were summarized by project and facility/reference area. Searcher efficiency (i.e., probability of detecting a carcass, assuming it was available to be detected) was calculated for each facility and reference area. Searcher efficiency was modeled, and fatalities were estimated using a distance sampling [31] approach commonly applied during postconstruction monitoring at utility scale PV USSE facilities in the U.S. (e.g., $[16,19,20])$. To generate standardized metric of fatalities, we calculated a fatality index for each site and paired facility and reference area where detections occurred. The fatality index $(f)$ was the sum of detections $(c)$ divided by the product of average searcher efficiency $(p)$ within each site and facility or reference area and the total area surveyed in each area $(a ;$ i.e., $f=\frac{c}{p * a}$ ) and used to compare the relative number of aquatic habitat bird fatalities in the facility and paired reference areas.

\section{Results}

In 2018, we completed 234 point count surveys at 3 PV USSE facilities, 229 point count surveys at 3 paired reference areas, 88 at Reference A, and 18 at Lake Tamarisk. In 2019, we completed 172 point count surveys at 3 solar facilities and 216 point count surveys at 3 paired reference areas; we completed 12 long-sit point counts (4 surveys per long-sit point count location at each study site in 2019). Over the 2 study periods at all study sites, we observed 4128 aquatic habitat birds of 26 species during point counts (Table 2). During long-sit point counts, we observed 299 aquatic habitat birds, representing 7 species. 


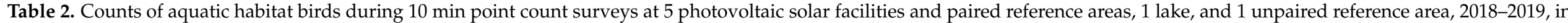
southern California, U.S. Data are counts of live birds from point counts (counts of bird carcasses from fatality surveys).

\begin{tabular}{|c|c|c|c|c|c|c|c|c|c|c|c|c|c|}
\hline \multirow{3}{*}{ Species Name } & \multicolumn{13}{|c|}{ Habitat and Study Site ${ }^{1}$} \\
\hline & \multicolumn{7}{|c|}{ Desert/Scrub } & \multicolumn{3}{|c|}{ Grassland } & \multicolumn{2}{|c|}{ Agricultural } & \multirow{2}{*}{ Total } \\
\hline & B-F & B-R & H-F & H-R & S-F & S-R & RA-R & LT-R & CVSR-F & CVSR-R & Mt. S-F & Mt. S-R & \\
\hline $\begin{array}{l}\text { American coot } \\
\text { Fulica americana }\end{array}$ & 0 & 0 & 0 & 0 & 0 & 0 & 0 & 1686 & 0 & 0 & $0(1)$ & $0(1)$ & $1686(2)$ \\
\hline $\begin{array}{l}\text { white-faced ibis } \\
\text { Plegadis chihi }\end{array}$ & 0 & 0 & 0 & 0 & 0 & 0 & 0 & 0 & $0(1)$ & 0 & 300 & $565(1)$ & $865(2)$ \\
\hline $\begin{array}{l}\text { cattle egret } \\
\text { Bubulcus ibis }\end{array}$ & 0 & 0 & 0 & 0 & 0 & 0 & 0 & 0 & 0 & 0 & 315 & $14(1)$ & $329(1)$ \\
\hline $\begin{array}{l}\text { red-winged blackbird } \\
\text { Agelaius phoeniceus }\end{array}$ & 0 & 0 & 0 & 0 & 0 & 0 & 0 & 0 & 0 & 0 & $80(1)$ & 240 & $320(1)$ \\
\hline $\begin{array}{c}\text { mallard } \\
\text { Anas platyrhynchos }\end{array}$ & 0 & 0 & 0 & 0 & $0(1)$ & 0 & 0 & 264 & 0 & 0 & 0 & 0 & $264(1)$ \\
\hline $\begin{array}{l}\text { ring-necked duck } \\
\text { Aythya collaris }\end{array}$ & 0 & 0 & 0 & 0 & 0 & 0 & 0 & 241 & 0 & 0 & 0 & 0 & 241 \\
\hline $\begin{array}{l}\text { ruddy duck } \\
\text { Oxyura jamaicensis }\end{array}$ & 0 & 0 & 0 & 0 & 0 & 0 & 0 & 119 & 0 & 0 & 0 & 0 & 119 \\
\hline $\begin{array}{l}\text { black-crowned night-heron } \\
\text { Nycticorax nycticorax }\end{array}$ & 0 & 1 & 0 & 0 & 0 & 0 & 0 & 60 & 0 & 0 & 0 & 0 & 61 \\
\hline $\begin{array}{c}\text { tree swallow } \\
\text { Tachycineta bicolor }\end{array}$ & 4 & 6 & 0 & 0 & 23 & 13 & 0 & 0 & 0 & 5 & 0 & 3 & 54 \\
\hline $\begin{array}{l}\text { pied-billed grebe } \\
\text { Podilymbus podiceps }\end{array}$ & 0 & 0 & 0 & 0 & 0 & 0 & 0 & 53 & 0 & 0 & 0 & 0 & 53 \\
\hline $\begin{array}{l}\text { great egret } \\
\text { Ardea alba }\end{array}$ & 0 & 0 & 1 & 0 & 0 & 4 & 0 & 6 & 0 & 0 & $6(1)$ & $31(1)$ & $48(2)$ \\
\hline $\begin{array}{l}\text { northern rough-winged swallow } \\
\text { Stelgidopteryx serripennis }\end{array}$ & 1 & 5 & 0 & 0 & 5 & 2 & 0 & 0 & 0 & 0 & 0 & 0 & 13 \\
\hline $\begin{array}{l}\text { double-crested cormorant } \\
\text { Phalacrocorax auritus }\end{array}$ & 0 & 0 & 0 & 0 & 0 & 0 & 0 & 0 & 0 & 0 & 13 & 0 & 13 \\
\hline $\begin{array}{l}\text { American wigeon } \\
\text { Mareca americana }\end{array}$ & 0 & 0 & 0 & 0 & 0 & 0 & 0 & 12 & 0 & 0 & 0 & 0 & 12 \\
\hline $\begin{array}{l}\text { yellow-headed blackbird } \\
\text { Xanthocephalus xanthocephalus }\end{array}$ & 0 & 0 & 1 & 10 & 0 & 0 & 0 & 1 & 0 & 0 & 0 & 0 & 12 \\
\hline
\end{tabular}


Table 2. Cont.

\begin{tabular}{|c|c|c|c|c|c|c|c|c|c|c|c|c|c|}
\hline \multirow{3}{*}{ Species Name } & \multicolumn{13}{|c|}{ Habitat and Study Site ${ }^{1}$} \\
\hline & \multicolumn{7}{|c|}{ Desert/Scrub } & \multicolumn{3}{|c|}{ Grassland } & \multicolumn{2}{|c|}{ Agricultural } & \multirow{2}{*}{ Total } \\
\hline & B-F & B-R & H-F & H-R & S-F & S-R & RA-R & LT-R & CVSR-F & CVSR-R & Mt. S-F & Mt. S-R & \\
\hline $\begin{array}{l}\text { northern shoveler } \\
\text { Spatula clypeata }\end{array}$ & 0 & 0 & 0 & 0 & 0 & 0 & 0 & 9 & 0 & 0 & 0 & 0 & 9 \\
\hline $\begin{array}{c}\text { cliff swallow } \\
\text { Petrochelidon pyrrhonota }\end{array}$ & 0 & 0 & 0 & 0 & 2 & 5 & 0 & 0 & 0 & 0 & 0 & 0 & 7 \\
\hline $\begin{array}{l}\text { belted kingfisher } \\
\text { Megaceryle alcyon }\end{array}$ & 0 & 0 & 0 & 0 & 0 & 0 & 0 & 5 & 0 & 0 & 0 & 1 & 6 \\
\hline $\begin{array}{l}\text { great blue heron } \\
\text { Ardea herodias }\end{array}$ & 0 & 0 & 1 & 0 & 0 & 0 & 0 & 0 & 0 & 0 & $0(1)$ & $4(1)$ & $5(2)$ \\
\hline $\begin{array}{c}\text { marsh wren } \\
\text { Cistothorus palustris }\end{array}$ & 0 & 0 & 0 & 0 & 0 & 0 & 0 & 4 & 0 & 0 & 0 & 0 & 4 \\
\hline $\begin{array}{c}\text { American avocet } \\
\text { Recurvirostra americana }\end{array}$ & 0 & 0 & 0 & 0 & 0 & 0 & 0 & 2 & 0 & 0 & 0 & 0 & 2 \\
\hline $\begin{array}{l}\text { lesser yellowlegs } \\
\text { Tringa flavipes }\end{array}$ & 0 & 0 & 0 & 0 & 0 & 0 & 0 & 1 & 0 & 0 & 0 & 0 & 1 \\
\hline $\begin{array}{l}\text { California gull } \\
\text { Larus californicus }\end{array}$ & 0 & 0 & 0 & 0 & 0 & 0 & 0 & 0 & 0 & 0 & 0 & 1 & 1 \\
\hline $\begin{array}{l}\text { green heron } \\
\text { Butorides virescens }\end{array}$ & 0 & 0 & 0 & 0 & 0 & 0 & 0 & 0 & 0 & 0 & 1 & 0 & 1 \\
\hline $\begin{array}{l}\text { greater yellowlegs } \\
\text { Tringa melanoleuca }\end{array}$ & 0 & 0 & 0 & 0 & 0 & 0 & 0 & 0 & 0 & 0 & 0 & 1 & 1 \\
\hline $\begin{array}{l}\text { blue-winged teal } \\
\text { Spatula discors }\end{array}$ & $0(1)$ & 0 & 0 & 0 & 0 & 0 & 0 & 0 & 0 & 0 & 0 & 0 & $0(1)$ \\
\hline $\begin{array}{l}\text { common loon } \\
\text { Gavia immer }\end{array}$ & 0 & 0 & 0 & 0 & $0(1)$ & 0 & 0 & 0 & 0 & 0 & 0 & 0 & $0(1)$ \\
\hline $\begin{array}{c}\text { western grebe } \\
\text { Aechmophorus occidentalis }\end{array}$ & 0 & 0 & 0 & 0 & 0 & 0 & 0 & 0 & 0 & 0 & 0 & $0(1)$ & $0(1)$ \\
\hline sora Porzana carolina & 0 & 0 & 0 & 0 & 0 & 0 & 0 & 0 & 0 & 0 & $0(1)$ & 0 & $0(1)$ \\
\hline Total & $5(1)$ & 12 & 3 & 11 & $30(2)$ & 24 & 0 & 2463 & $0(1)$ & 5 & 715 (5) & $860(6)$ & 4128 (15) \\
\hline
\end{tabular}

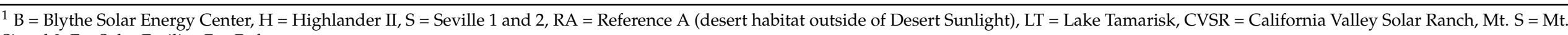
Signal 3; F = Solar Facility, R = Reference. 
3.1. Species Richness and Community Association of Live Aquatic Habitat Birds at Photovoltaic Solar and Reference Areas

We examined patterns in the relative frequency of occurrence to determine whether aquatic habitat birds occurred more frequently at the PV solar site than at the paired reference area. For the sites in the desert/scrub habitat, we found that of the 8 aquatic habitat species observed during point counts, 4 species $(50 \%)$ occurred more frequently in the reference areas than in the solar facilities. For the site in the agricultural habitat, we found that of the 11 aquatic habitat species observed during point counts, 6 species (55\%) occurred more frequently in the reference areas than in the solar facility. Aquatic habitat birds were not observed during point counts at the solar facility area in the grassland ecoregion, and only a single species was observed in the reference area (tree swallow (Tachycineta bicolor $)$ ). We found no statistically significant difference $\left(\chi^{2}=0.0297, p=0.8633\right)$ in the distribution of aquatic habitat birds between facility and reference areas, accounting for habitat. The test result is consistent with the qualitative analysis of relative frequencies of aquatic habitat birds by habitat in that aquatic habitat bird species did not appear in higher relative frequency in facility areas compared with reference areas.

We examined patterns in species diversity and use to determine how the aquatic habitat bird community at PV solar facilities compares with a regional lake. Using Chao's [26,27] estimator, richness was estimated for live aquatic habitat birds to be highest at the lake $(14.5$, SD = 1.28; Table 3), which was $20.8 \%$ higher than the strata with the next highest richness estimate (agriculture reference, $12, \mathrm{SDE}=4.48$; Table 3 ). The remaining strata where aquatic habitat birds were observed during point counts (agriculture facility, desert facility, desert reference, and grassland reference) had richness estimates between 1 and 7 for aquatic habitat species. However, $90 \%$ confidence intervals generally overlapped between all strata, and it was not clear whether there were any statistically significant differences in Chao's estimate between any two strata (Table 3). Among the strata with bird fatality detections, there was a high degree of variability (Table 4). The agriculture reference area had the highest Chao's estimate $(21, \mathrm{SD}=13.46$; Table 4$)$, followed in rank by agriculture facility, desert facility, and grassland facility (no aquatic habitat birds were found during fatality monitoring in the grassland or desert reference areas). However, due to the small number of aquatic habitat birds detected during fatality monitoring, the standard deviation was large relative to richness estimates. The percent coefficient of variation $(100 \times$ estimate/standard deviation) was between $64 \%$ and $71 \%$ for the strata with more than one aquatic habitat bird fatality, and $90 \%$ confidence intervals were wide compared with the live bird data and largely overlapping for all strata (Table 4). We also qualitatively compared the mean avian use and fatality index of aquatic habitat birds within each stratum to account for differences in use, fatality rate, and effort associated with each site (Figure 2). The results were consistent, if not more pronounced than the comparison of species richness, with the lake showing an order of magnitude higher use by aquatic habitat species (10 observations/point/visit) compared with the next highest site, agriculture facility ( 0.75 observation/point/visit; Figure 3 ).

Table 3. Species richness and Chao's estimator of richness for aquatic habitat birds observed during live bird counts in 3 habitat regions and a lake. Birds unidentifiable to species were excluded from species richness calculations.

\begin{tabular}{cccccccc}
\hline & $\begin{array}{c}\text { Reference- } \\
\text { Lake }\end{array}$ & $\begin{array}{c}\text { Facility- } \\
\text { Desert }\end{array}$ & $\begin{array}{c}\text { Reference- } \\
\text { Desert }\end{array}$ & $\begin{array}{c}\text { Facility- } \\
\text { Agriculture }\end{array}$ & $\begin{array}{c}\text { Reference- } \\
\text { Agriculture }\end{array}$ & $\begin{array}{c}\text { Facility- } \\
\text { Grassland }\end{array}$ & $\begin{array}{c}\text { Reference- } \\
\text { Grassland }\end{array}$ \\
\hline Species richness & 14 & 6 & 7 & 6 & 9 & 0 & 1 \\
Chao's estimator & 14.5 & 7.5 & 8 & 6 & 12 & NA & 1 \\
$\begin{array}{c}\text { Standard deviation } \\
\text { 90\% Confidence } \\
\text { interval }\end{array}$ & 1.28 & 2.54 & 2.24 & 0.46 & 4.48 & NA & 0 \\
14.05-19.20 & $6.22-16.16$ & $7.11-16.04$ & $6-\mathrm{NA}$ & $9.51-26.81$ & NA & NA \\
\hline
\end{tabular}



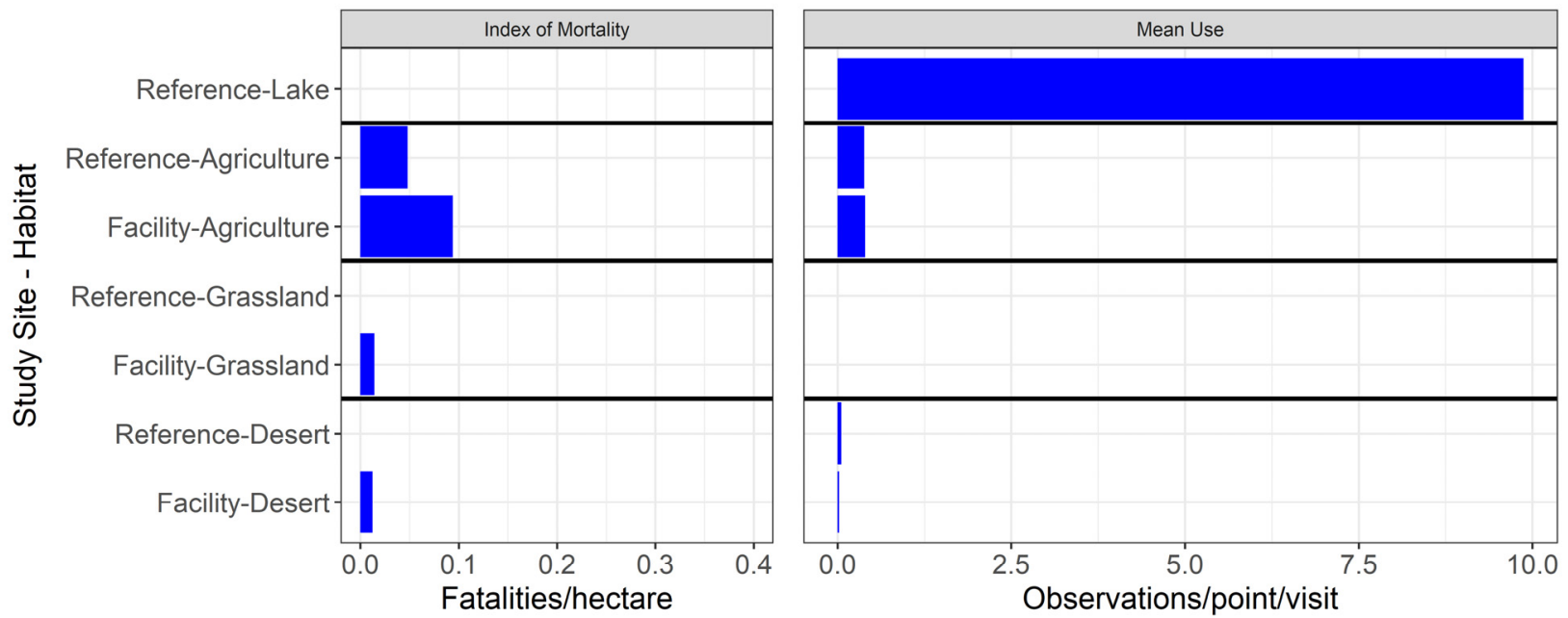

Figure 2. Index of mortality (found fatalities per hectare of area searched, adjusted for searcher efficiency) and mean use (live birds counted per point per survey visit) of aquatic habitat birds found at the facility and reference survey areas in 3 habitat regions and a lake (no fatality surveys occurred at the lake).

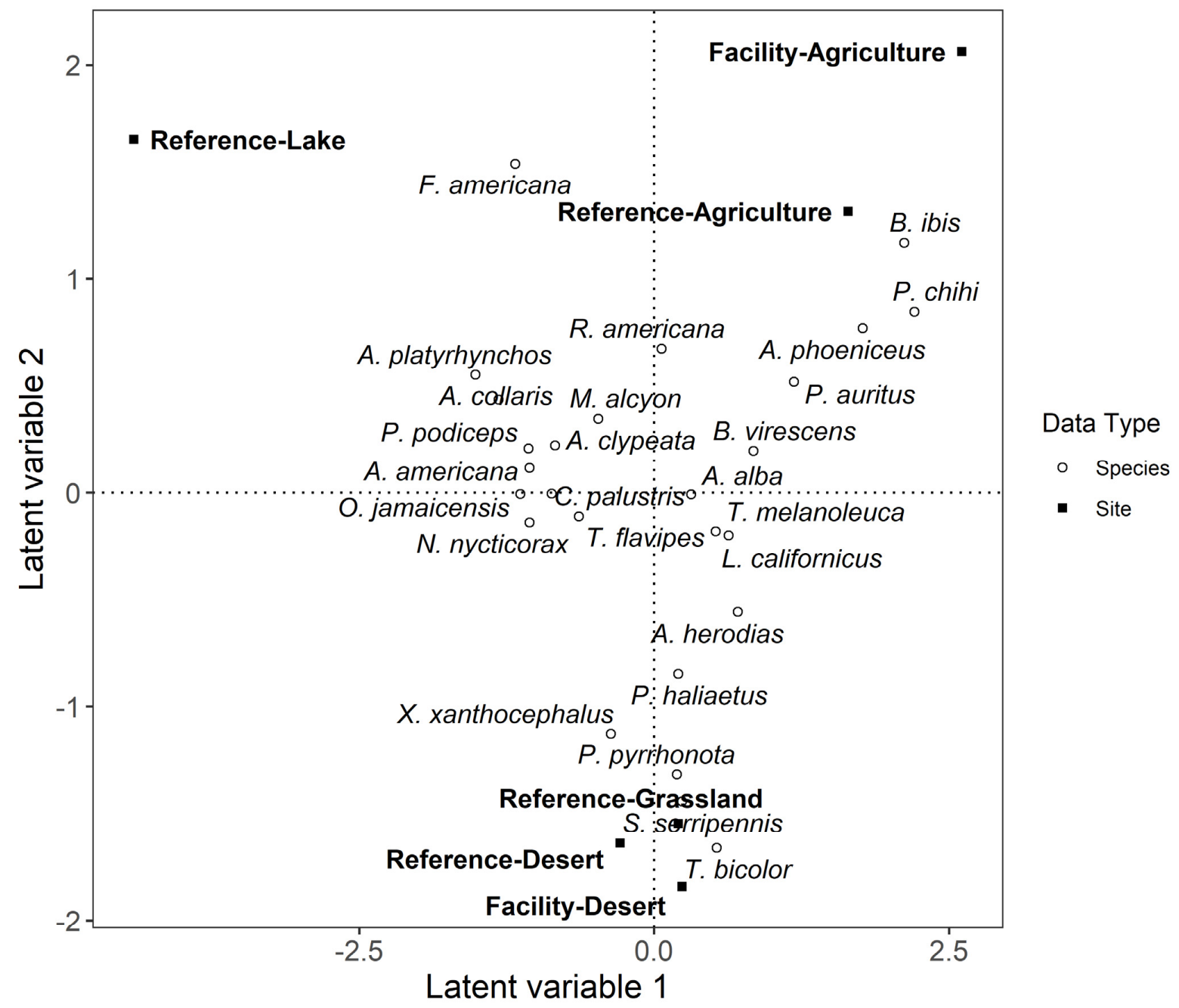

Figure 3. Ordination of aquatic habitat species observed during point count surveys and facility or reference areas in 3 habitat regions based on 2 latent variables in a Bayesian ordination and regression analysis. No aquatic habitat birds were observed in the facility-grassland stratum. 
Table 4. Species richness and Chao's estimator of richness for aquatic habitat birds detected as fatalities at facility and reference survey areas in 3 habitat regions. Birds unidentifiable to species were excluded from species richness calculations.

\begin{tabular}{|c|c|c|c|c|c|c|}
\hline & $\begin{array}{l}\text { Facility- } \\
\text { Desert }\end{array}$ & $\begin{array}{c}\text { Reference- } \\
\text { Desert }\end{array}$ & $\begin{array}{c}\text { Facility- } \\
\text { Agriculture }\end{array}$ & $\begin{array}{l}\text { Reference- } \\
\text { Agriculture }\end{array}$ & $\begin{array}{l}\text { Facility- } \\
\text { Grassland }\end{array}$ & $\begin{array}{l}\text { Reference- } \\
\text { Grassland }\end{array}$ \\
\hline Species richness & 3 & 0 & 5 & 6 & 1 & 0 \\
\hline Chao's estimator & 6 & NA & 15 & 21 & 1 & NA \\
\hline Standard deviation & 4.29 & NA & 10.04 & 13.46 & 0 & NA \\
\hline $\begin{array}{c}90 \% \text { Confidence } \\
\text { interval }\end{array}$ & $3.53-20.00$ & NA & $7.53-44.49$ & $10.24-59.09$ & NA & NA \\
\hline
\end{tabular}

$\mathrm{NA}=$ not applicable

Ordination of live bird data supported the separation of study sites into three groupings (Figure 3). The lake grouped away from all other combinations of habitat and facility/ reference. The desert facility and reference areas grouped with the grassland reference area, and the agricultural areas grouped together. Heron, egret, and blackbird species also tended to group closer to the agricultural site, whereas grebes, coots (Fulica spp.), and ducks tended to group towards the lake and desert/grassland cluster to a lesser extent.

\subsection{Mortality of Aquatic Habitat Birds at Photovoltaic Solar and Reference Areas}

During the 2018 field season, we deployed 201 searcher efficiency trials across the sites (90 large bird trials and 111 small bird trials), including 87 trials in facility areas and 114 trials in reference areas (Supplementary Material Table S3). In 2019, we deployed 144 trials (78 large bird trials and 66 small bird trials), including 70 trials in facility areas and 74 trials in reference areas. No trials were placed at Blythe facility areas, which had an existing bias trial dataset resulting from over 2 years of standardized fatality monitoring (95 m row lengths), and Reference A given the proximity and similarity to Blythe reference areas. Furthermore, no trials could be placed in any area at the Mt. Signal site due to access restrictions. The ground conditions (e.g., amount of visible bare ground, presence of rubble or vegetation, typical vegetation height, and density when present) at Mt. Signal were more similar to Seville (facility and reference areas) than any other site monitored during the study. Thus, we assumed the probability of detection in the facility and reference areas of Mt. Signal would be comparable to Seville, and modeled searcher efficiency for Mt. Signal using the 2019 Seville data.

Searcher efficiency varied by study site and whether trials were in the facility or reference area. The best-fit model for 2018 facility areas was a half-normal detection function and included a covariate for study site (i.e., systematic differences in search efficiency by facility) for both small and large birds (Supplementary Material Table S4). The top model for reference areas in 2018 did not include any covariates (i.e., no systematic differences in search efficiency by facility) and was a half-normal detection function for large birds and a hazard detection function for small birds. In 2019, the best-fit model for facility areas included study site and was a uniform detection function for small birds, while the large bird model for facility did not include any covariates and used a halfnormal detection function. In the reference areas, both small birds and large birds used an exponential detection function and included study site as a covariate.

Within the facility area and reference area of each study site, respectively, searcher efficiency was generally lower for small birds compared with large birds in each year (Figure 4). In 2018, average searcher efficiency in the facility areas ranged between 0.38 $(\mathrm{SE}=0.03)$ and $0.69(\mathrm{SE}=0.09)$ for small birds, and between $0.53(\mathrm{SE}=0.03)$ and $1.0(\mathrm{SE}=0)$ for large birds; average searcher efficiency in the reference areas ranged between 0.31 $(\mathrm{SE}=0.12)$ and $0.41(\mathrm{SE}=0.10)$ for small birds, and between $0.74(\mathrm{SE}=0.14)$ and 0.92 for large birds. In 2019, average searcher efficiency in the facility areas ranged between 0.38 $(\mathrm{SE}=0.12)$ and $0.72(\mathrm{SE}=0.12)$ for small birds, and between $0.93(\mathrm{SE}=0.05)$ and 0.98 $(\mathrm{SE}=0.03)$ for large birds; average searcher efficiency in the reference areas ranged between 
$0.30(\mathrm{SE}=0.10)$ and $0.76(\mathrm{SE}=0.11)$ for small birds, and between $0.54(\mathrm{SE}=0.11)$ and 0.75 $(\mathrm{SE}=0.10)$ for large birds.

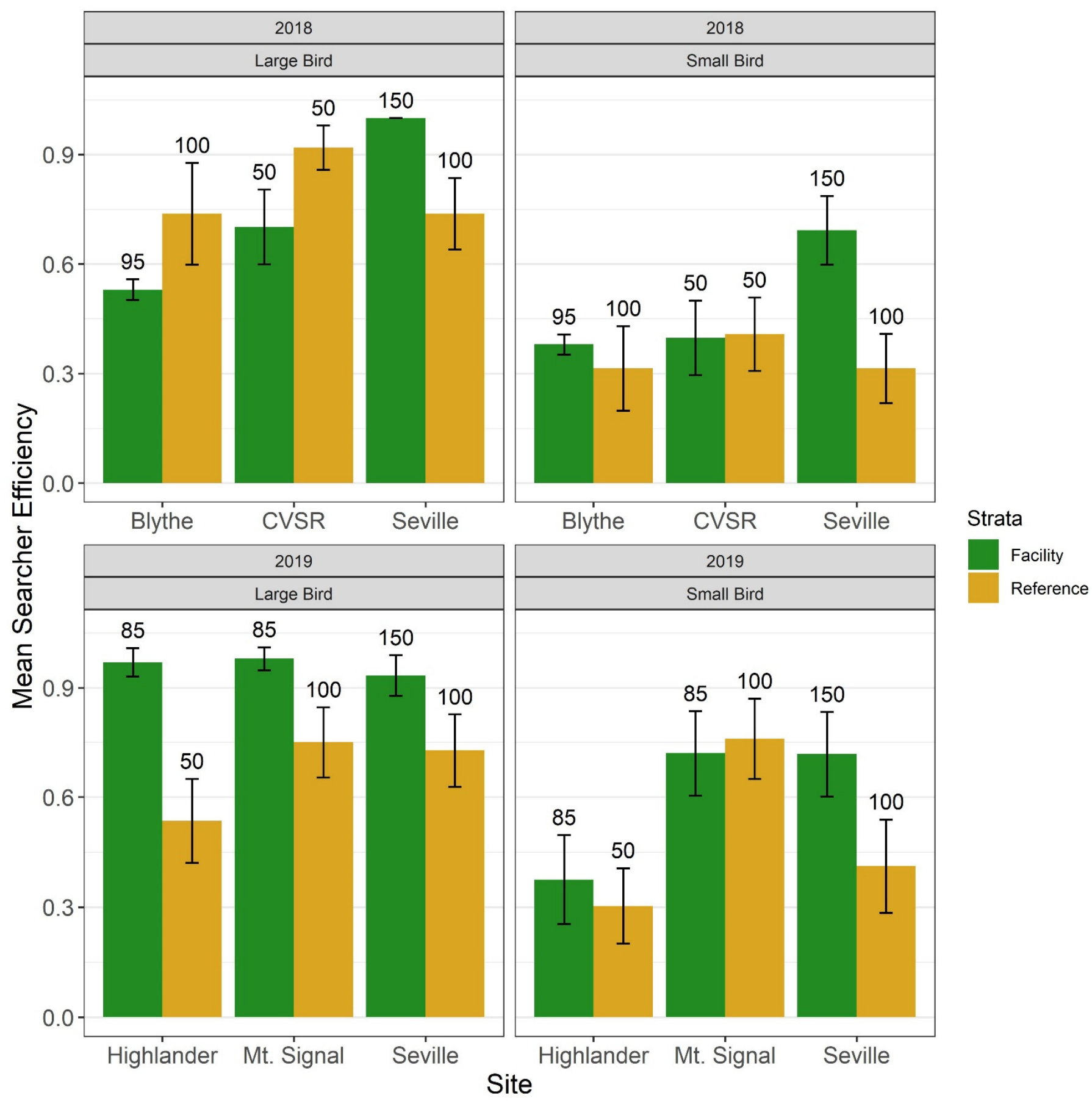

Figure 4. Mean searcher efficiency by bird size category and study site used to calculate the index of mortality. Viewshed sampling distance (in meters) is indicated above each column. Error bars show mean +/- one standard error.

There were 15 detections of aquatic habitat species across all study sites and years of study, ranging from 0 ( 6 of the 11 combinations of site and facility or reference) to 6 (Mt. Signal reference area). Given the small number of detections relative to total hectares surveyed, the fatality index for aquatic habitat species showed little variability within the 2-week study periods at each study site, ranging from 0 (grassland reference) to 0.09 fatalities/ha/study period (agriculture facility; Figure 2). Thus, fatalities were not 
distinctly higher in the reference or facility areas of any site, accounting for differences in searcher efficiency by site and facility or reference area, and different amounts of total area searched.

\section{Discussion}

The LEH was developed from mortality patterns at PV USSE facilities, and researchers suggested that the PV facility provided a signal of water to aquatic habitat birds [3]. However, data gaps exist in our understanding of the LEH as live bird behavior at PV solar facilities had not been examined, nor had an alternative to the LEH been considered. Further, context for the number of carcasses detected is lacking as aquatic habitat bird mortality had never been evaluated against the bird community at a regional waterbody. We found that live aquatic habitat birds occurred at PV solar facilities, but we did not observe flocks approaching the solar sites exhibiting landing behavior. We found that aquatic habitat bird diversity was lower at PV USSE facilities compared with Lake Tamarisk, and standardized use was more than an order of magnitude higher at Lake Tamarisk than what we found at the PV USSE facilities. We did not locate aquatic habitat bird detections in the desert/scrub and grassland reference areas; thus, we did not find support for the alternative hypothesis that mortality is independent of the PV facility. Taken together, we cannot readily generalize the LEH to all aquatic habitat birds, and fatality risk could be species specific and context dependent.

If aquatic habitat birds are attracted to PV solar facilities across taxa, we would expect to find, in addition to fatality detections, live aquatic habitat birds approaching or perched at the facility. Our results show that aquatic habitat birds were infrequently observed at the desert/scrub and grassland study sites, and we found no evidence of the expression of maladaptive behaviors, such as landing attempts or flocks repeatedly circling a facility. Rather, our observations were of aquatic habitat birds transitioning the facility, and the same species were often observed in the paired reference area. As our study did not include nocturnal sampling using radar or other methods, we would not have detected birds moving outside of our sampling period. Some species of aquatic habitat birds found as detections in this study and in Kosciuch et al. [4] migrate nocturnally (e.g., [32]), and it is possible that aquatic habitat bird exposure at the PV facilities nocturnally was higher than we measured diurnally. However, species resolution is limited with radar, and interpreting patterns in the context of the LEH could be challenging. Thus, our point count results demonstrate limitations in understanding the extent of a potential lake effect when interpreting diurnal patterns of live aquatic habitat bird occurrences at PV solar facilities. Overall, diurnal point count surveys for aquatic habitat birds are unlikely to provide data to predict the number of fatalities of these species.

Mt. Signal, the PV solar facility and paired reference area in the agriculture habitat, differed from our other study sites having higher aquatic habitat bird diversity, use, and detections. Mt. Signal is developed in a landscape that has been altered by irrigation from the Salton Sea, where irrigation and farming have converted the agricultural habitat into a novel ecosystem with a high level of human disturbance and changes to the biota reflected in the bird community [33]. It follows that aquatic habitat bird use was higher in an irrigated landscape compared with a grassland and desert/scrub habitat; however, the mortality patterns at PV solar facilities in agricultural landscapes are poorly studied [4]. The adjusted fatalities/ha was similar between the facility and reference site for Mt. Signal, suggesting that mortality risk is not isolated to the solar facility. Thus, in the agricultural landscape context, it is difficult to untangle attraction (i.e., lake effect) from other sources of mortality (e.g., predation) for some species. Arid landscapes without water in close proximity to PV USSE facilities, such as our desert/scrub study sites, provide more inference into the LEH because possible attraction is obscured in agricultural landscapes, which can be hybrid or novel ecosystems inhabited by aquatic habitat birds.

The premise of the LEH is that PV USSE facilities attract aquatic habitat birds, but the magnitude of attraction has not been suggested, leaving a gap in our understanding of 
how aquatic habitat bird abundance and diversity at a PV USSE facility compares with a natural waterbody. No aspect of the LEH limits the number of live or dead aquatic habitat birds that could occur at a PV solar facility, and the expression of maladaptive behaviors could lead to exaggerated patterns (e.g., [34]). The major waterbody in the vicinity of the study sites in the desert/scrub and agricultural habitat is the Salton Sea, an approximately 89,000 ha saline lake that is a known stopover location for hundreds of thousands of aquatic habitat birds [35]. As none of our PV USSE sites approached the size of the Salton Sea, we surveyed Lake Tamarisk, a 5.5 ha artificial lake in a desert community, and counted thousands of birds over our sampling period, showing the importance of waterbodies in this arid environment. Lake Tamarisk grouped away from the solar facilities and paired reference areas in the multivariate analysis and had 25-800 times the abundance of aquatic habitat birds compared with the PV USSE sites, including the site in the agricultural habitat where aquatic habitat birds were part of the local bird community. Our surveys at Lake Tamarisk included birds that were foraging or loafing on the lake, which is not possible at a PV USSE facility. Thus, it follows that mean use was higher at Lake Tamarisk than at the PV USSE facilities. However, understanding the regional aquatic habitat bird community at a waterbody is important for research questions related to the magnitude of the LEH and predicting aquatic habitat bird occurrence. Although waterbodies are scarce in the desert/scrub habitat near our study sites, had we surveyed a different lake, the results would likely have differed. However, our sample of one lake in a water-limited environment does not alter our conclusions about context for understanding the potential availability of birds that could occur at PV solar facilities in our study.

Developing alternatives to a hypothesis established through abduction is important so that the original hypothesis is not accepted by default [36,37]. An alternative hypothesis to the LEH is that ill or exhausted birds land randomly on a landscape, including PV USSE facilities. Thus, under a random landing hypothesis, an aquatic habitat bird detection would be equally likely to occur outside of a PV USSE facility as inside a facility. Given that there was no reference area monitoring associated with 9 of 10 PV USSE sites summarized by Kosciuch et al. [4], it is possible that broader patterns of mortality were not detected because of the survey methods used in those studies. The occurrence of water-obligate species, such as loons and grebes, on dry land away from water is maladaptive because these species become stranded and ultimately perish on dry land [38]. Thus, there is no evolutionary context for a common loon (Gavia immer, a species detected as a fatality at our Seville study site) to occur in the desert on dry land. The presence of aquatic habitat bird detections found at PV USSE facilities in a desert/scrub habitat provides the most compelling evidence that these individuals were attracted to the facility because fatalities were not found in the paired reference areas. We found no aquatic habitat bird detections in Reference A, which was located outside of Desert Sunlight, the site in Kosciuch et al. [4] that had the highest number ( $n=94$ detections over 2 full years of monitoring) and proportion of aquatic bird detections among PV arrays among the 10 sites summarized. Thus, if a mechanism other than attraction was responsible for aquatic habitat bird detections at PV solar facilities (e.g., exhaustion and random landing), we would have expected to find aquatic habitat bird detections in Reference A, assuming detections continued in the facility.

We found aquatic habitat bird detections at all PV facilities and in the agricultural site reference area, but not at reference areas in a desert/scrub or grassland habitat. Searcher efficiency was similar at the PV facilities and reference areas with three exceptions where the value at the reference area was approximately half that at the paired PV facility. Large difference in searcher efficiency between PV facility and reference area could limit our conclusions about mortality patterns. However, we searched a larger area at the reference areas and accounted for these differences in the fatality index. Although we did not perform carcass persistence trials as is common for fatality-monitoring studies, our goal was not to produce robust estimates of fatalities as summarized in Kosciuch et al. [4] —rather, it was to have a high likelihood of detecting aquatic habitat species as fatalities, were they to occur. Furthermore, we assumed carcass persistence was similar in facility and reference areas, 
and the frequency of searches ( $<48 \mathrm{~h}$ apart) would limit potential bias from different rates of carcass removal by scavengers in either area.

\section{Conclusions}

The idea of "lake effect" in which birds perceive a PV USSE facility as a waterbody (or the facility creates a lake effect) and are attracted is likely a nuanced process as a PV solar facility is unlikely to provide a signal of a lake to all aquatic habitat birds at all times. The results from our study suggest that some species of aquatic habitat birds could be attracted to PV USSE facilities, and if attraction occurs, it is likely context dependent. The most compelling evidence for attraction is the mortality of water-obligate species (e.g., loons) found at PV USSE facilities in desert environments that lack water, as these species perish on dry land. Untangling mortality at PV solar facilities in landscapes with other anthropogenic features is challenging for many species because of the potential for facilityindependent mortality (i.e., background mortality). Data from Lake Tamarisk suggested that mortality at the PV USSE facilities was low compared with the abundance and diversity of birds regionally. However, our sampling methods did not measure nocturnal exposure; thus, if aquatic habitat birds were moving nocturnally, we would have underestimated sitespecific exposure. Our study shows that a primary limitation of predicting whether aquatic habitat bird mortality will occur is that the causal mechanism is not understood, which could involve complex interactions of the species and the facility. Thus, understanding potential risk at future PV USSE facilities is currently best informed by the regional context of the facility, as suggested by Kosciuch et al. [4]. However, it is unknown how other landscape contexts outside of our study region and the availability of natural waterbodies will influence aquatic habitat bird behavior at PV USSE facilities.

Supplementary Materials: The following are available online at https:/ /www.mdpi.com/article/10 .3390/d13110524/s1: Table S1: Number of fixed-point locations at solar facilities and reference areas by site, Table S2: Viewshed (meters) used for fatality monitoring with the solar field and in reference areas, and total survey area (hectares) at 5 study sites over 2 years, Table S3: Number of searcher efficiency trials deployed by site, strata type, bird size category, and year, Table S4: Candidate searcher efficiency models, AICc, $\triangle \mathrm{AIC}$, and selected models for estimating searcher efficiency for small birds and large birds and fatality transects in the facility and reference areas, by year.

Author Contributions: Conceptualization, K.K., D.R.-E. and W.E.; methodology, K.K., D.R.-E., C.M. and W.E.; formal analysis, D.R.-E.; investigation, K.K., D.R.-E. and C.M.; data curation, D.R.-E. and C.M.; writing—original draft preparation, K.K., D.R.-E. and C.M.; writing—review and editing, W.E.; visualization, K.K. and D.R.-E.; supervision, K.K.; project administration, K.K. and C.M.; funding acquisition, K.K. and W.E. All authors have read and agreed to the published version of the manuscript.

Funding: This research was funded by the California Energy Commission (SCH number 2017058525), including matching funds from 8minute Solar Energy, Duke Energy, First Solar, NextEra Energy, NRG Energy, and Recurrent Energy.

Institutional Review Board Statement: Not applicable.

Data Availability Statement: Data is contained in the article or supplementary material.

Acknowledgments: Erik Jansen provided comments on a previous draft of this manuscript, and Lauren Schell provided administrative support. We thank the field biologists that collected the data used in this study, especially Brandon Miller, Christina Van Oosten, and Jen Wilcox, who provided 2 years of support. Tracey Johnson provided valuable comments on study design.

Conflicts of Interest: The funders had no role in the design of the study; in the collection, analyses, or interpretation of data; in the writing of the manuscript; or in the decision to publish the results. 


\section{References}

1. Lovich, J.E.; Ennen, J.R. Wildlife conservation and solar energy development in the desert Southwest, United States. Biosci 2011, 61, 982-992. [CrossRef]

2. Guerra, K.; Dahm, K.; Dundorf, S. Oil and Gas Produced Water Management and Beneficial Use in the Western United States; US Department of the Interior, Bureau of Reclamation Denver: Lakewood, CO, USA, 2011. Available online: https://www.usbr.gov/ research/dwpr/reportpdfs/report157.pdf (accessed on 31 December 2020).

3. Kagan, R.A.; Viner, T.C.; Trail, P.W.; Espinoza, E.O. Avian Mortality at Solar Energy Facilities in Southern California: A Preliminary Analysis; National Fish and Wildlife Forensics Laboratory, U.S. Fish and Wildlife Service: Ashland, OR, USA, 2014.

4. Kosciuch, K.; Riser-Espinoza, D.; Gerringer, M.; Erickson, W. A summary of bird mortality at photovoltaic utility scale solar facilities in the southwestern U.S. PLoS ONE 2020, 15, e0232034. [CrossRef] [PubMed]

5. Loss, S.R.; Will, T.; Loss, S.S.; Mara, P.P. Bird-building collisions in the United States: Estimates of annual mortality and species vulnerability. Condor 2014, 116, 8-23. [CrossRef]

6. Gehring, J.; Kerlinger, P.; Manville, A.M., II. The role of tower height and guy wires on avian collisions with communication towers. J. Wildl. Manag. 2011, 75, 848-855. [CrossRef]

7. Loss, S.R.; Will, T.; Marra, P.P. Estimates of Bird Collision Mortality at Wind Facilities in the Contiguous United States. Biol. Conserv. 2013, 168, 201-209. [CrossRef]

8. Erickson, W.P.; Wolfe, M.M.; Bay, K.J.; Johnson, D.H.; Gehring, J.L. A comprehensive analysis of small passerine fatalities from collisions with turbines at wind energy facilities. PLoS ONE 2014, 9, 107491. [CrossRef] [PubMed]

9. Solar Farms Threaten Birds. Available online: https://www.scientificamerican.com/article/solar-farms-threaten-birds/ (accessed on 27 July 2021).

10. Conkling, T.J.; Loss, S.R.; Diffendorfer, J.E.; Duerr, A.E.; Katzner, T.E. Limitations, lack of standardization, and recommended best practices in studies of renewable energy effects on birds and bats. Conserv. Biol. 2020, 35, 64-76. [CrossRef] [PubMed]

11. Yang, L.; Jin, S.; Danielson, P.; Homer, C.; Gass, L.; Bender, S.M.; Case, A.; Costello, C.; Dewitz, J.; Fry, J.; et al. A new generation of the United States National Land Cover Database: Requirements, research priorities, design, and implementation strategies. ISPRS J. Photogramm. Remote Sens. 2018, 146, 108-123. [CrossRef]

12. Multi-Resolution Land Characteristics Consortium. National Land Cover Database (NLCD) 2016; Multi-Resolution Land Characteristics Consortium: Sioux Falls, SD, USA, 2019.

13. Ralph, C.J.; Sauer, J.R.; Droege, S. Monitoring Bird Populations by Point Counts; Pacific Southwest Research Station, US Department of Agriculture, Forest Service: Albany, CA, USA, 1995. Available online: https://www.fs.fed.us/psw/publications/documents/ psw_gtr149/ (accessed on 27 July 2021).

14. Buckland, S.T.; Anderson, D.R.; Burnham, K.P.; Laake, J.L.; Borchers, D.L.; Thomas, L.J. An Introduction to Distance Sampling: Estimating Abundance of Biological Populations; Oxford University Press: Oxford, UK, 2001.

15. Buckland, S.T.; Anderson, D.R.; Burnham, K.P.; Laake, J.L.; Borchers, D.L.; Thomas, L. Advanced Distance Sampling; Oxford University Press: Oxford, UK, 2004.

16. Huso, M.; Dietsch, T.; Nicolai, C. Mortality Monitoring Design for Utility-Scale Solar Power Facilities; U.S. Geological Survey: Reston, VA, USA, 2016. Available online: https:/ / pubs.er.usgs.gov/publication/ofr20161087 (accessed on 27 July 2021). [CrossRef]

17. H.T. Harvey \& Associates. Ivanpah Solar Electric Generating System Avian \& Bat Monitoring Plan. 2013-2014 Annual Report (Revised): (29 October 2013-20 October 2014); H.T. Harvey \& Associates: Los Gatos, CA, USA, 2015. Available online: https: / / efiling.energy.ca.gov / GetDocument.aspx?tn=204258\&DocumentContentId=2191 (accessed on 27 July 2021).

18. Martinson, L.; Gerringer, M.; Lombardi, J.; (Western EcoSystems Technology, Inc., Cheyenne, WY, USA). Post-construction monitoring at the Blythe Solar Power Project, Riverside County, California. Second annual report draft: 2017-2018. Personal communication, 2019.

19. Western EcoSystems Technology, Inc. Ivanpah Solar Electric Generating System Avian E Bat Monitoring Plan: 2014-2015 Annual Report, and Two Year Comparison: 21 October 2014-20 October 2015; Western EcoSystems Technology, Inc.: Cheyenne, WY, USA, 2016.

20. Western EcoSystems Technology, Inc. Ivanpah Solar Electric Generating System Avian E Bat Monitoring Plan: 2015-2016 Annual Report; Western EcoSystems Technology, Inc.: Cheyenne, WY, USA, 2017. Available online: https:/ / efiling.energy.ca.gov/Lists/ DocketLog.aspx?docketnumber=07-AFC-05C (accessed on 27 July 2021).

21. Western EcoSystems Technology, Inc.; (Cheyenne, WY, USA). Post-construction monitoring at the Blythe Solar Power Project, Riverside County, California. First annual report draft: 2016-2017. Personal communication, 2018.

22. U.S. Fish and Wildlife Service. Land-Based Wind Energy Guidelines; U.S. Fish and Wildlife Service: Washington, DC, USA, 2012. Available online: http:/ / www.fws.gov / cno/pdf/Energy /2012_Wind_Energy_Guidelines_final.pdf (accessed on 27 July 2021).

23. Caplat, P.; Fonderflick, J. Area mediated shifts in bird community composition: A study on a fragmented Mediterranean grassland. Biodivers. Conserv. 2009, 18, 2979-2995. [CrossRef]

24. Visser, E.; Perold, V.; Ralston-Paton, S.; Cardenal, A.C.; Ryan, P.G. Assessing the impacts of a utility-scale photovoltaic solar energy facility on birds in the Northern Cape, South Africa. Renew. Energy 2019, 133, 1285-1294. [CrossRef]

25. Cornell Lab of Ornithology. All about Birds. Available online: https: / / www.allaboutbirds.org (accessed on 31 December 2020).

26. Chao, A. Estimating the population size for capture-recapture data with unequal catchability. Biometrics 1987, 43, 783-791. [CrossRef] [PubMed] 
27. Chiu, C.H.; Wang, Y.T.; Walther, B.A.; Chao, A. Improved nonparametric lower bound of species richness via a modified Good-Turing frequency formula. Biometrics 2014, 70, 671-682. [CrossRef] [PubMed]

28. Vegan: Community Ecology Package (version 2.5-7). Available online: https://CRAN.R-project.org/package=vegan (accessed on 17 September 2021).

29. Boral: Bayesian Ordination and Regression Analysis (version 2.0). Available online: https://cran.r-project.org/web/packages / boral/index.html (accessed on 17 September 2021).

30. Hui, F.K.C. Boral: Bayesian ordination and regression analysis of multivariate abundance data in R. Methods Ecol. Evol. 2016, 7, 744-750. [CrossRef]

31. Buckland, S.T.; Anderson, D.R.; Burnham, K.P.; Laake, J.L. Distance Sampling: Estimating Abundance of Biological Populations; Chapman \& Hall: London, UK, 1993.

32. LaPorte, N.; Storer, R.W.; Nuechterlein, G.L. Western Grebe (Aechmophorus occidentalis), version 1.0. In Birds of the World; Rodewald, P.G., Ed.; Cornell Lab of Ornithology: Ithaca, NY, USA, 2020. [CrossRef]

33. Hobbs, R.J.; Higgs, E.; Harris, J.A. Novel ecosystems: Implications for conservation and restoration. Trends Ecol. Evol. 2009, 24, 599-605. [CrossRef] [PubMed]

34. Robertson, B.A.; Blumstein, D.T. How to disarm and evolutionary trap. Conserv. Sci. Pract. 2019, 1, e116. [CrossRef]

35. Shuford, W.D.; Warnock, N.; Molina, K.C.; Sturm, K.K. The Salton Sea as critical habitat to migratory and resident waterbirds. In The Salton Sea: Developments in Hydrobiology; Barnum, D.A., Elder, J.F., Stephens, D., Friend, M., Eds.; Springer: Dordrecht, The Netherlands, 2002; Volume 161, pp. 255-274. [CrossRef]

36. Josephson, J.; Josephson, S. Abductive Inference; Cambridge University Press: Cambridge, UK, 1996.

37. Kosciuch, K.L.; Parker, T.H.; Sandercock, B.K. Nest desertion by a cowbird host: An antiparasite behavior or a response to egg loss? Behav. Ecol. 2006, 17, 917-924. [CrossRef]

38. Robertson, B.A.; Chalfoun, A.D. Evolutionary traps as keys to understanding behavioral maladaptation. Curr. Opin. Behav. Sci. 2016, 12, 12-17. [CrossRef] 